\title{
Modeling of Inactivation of Biofilm Composing Bacteria with Low Intensity Electric Field: Prediction of Lowest Intensity and Mechanism
}

\author{
Mokhamad Tirono ${ }^{1 *}$ and Suhariningsih ${ }^{2}$ \\ ${ }^{1}$ Physics Department, Faculty of Science and Technology, Universitas Islam Negeri Maulana Malik Ibrahim \\ Malang, Malang, East Java, Indonesia \\ ${ }^{2}$ Physics Department, Faculty of Science and Technology, Airlangga University, Surabaya, East Java, Indonesia
}

\begin{abstract}
Sterilization using high-intensity electric fields is detrimental to health if safety is inadequate, so it is necessary to study the possibility of sterilization using low-intensity electric fields. This study aims to determine the lowest electric field intensity and treatment time to deactivate the bacteria that make up the biofilms and explain the mechanism of inactivation. The study samples were biofilms from the bacteria Pseudomonas aeruginosa and Staphylococcus epidermidis grown on the catheter. The modeling formula was developed from the Pockels effect and the Weibull distribution with the treatment using a square pulse-shaped electric field with a pulse width of $50 \mu$ s and an intensity of 2.0-4.0 kV/ $\mathrm{cm}$. The results showed that the threshold for irreversible electroporation of both samples occurred in the treatment using an electric field with an intensity of $3.5 \mathrm{kV} / \mathrm{cm}$ and $3.75 \mathrm{kV} /$ $\mathrm{cm}$, respectively, where the size and type of Gram of bacteria influenced. Moreover, the time of the treatment had an effect when irreversible electroporation occurred. However, when there was reversible electroporation, the effect of treatment time on the reduction in the number of bacteria was not significant. Also, changes in conductivity affected the reduction in the number of bacteria when reversible electroporation occurred.
\end{abstract}

Keywords: Bacteria, biofilms, electric field, electroporation, reduction

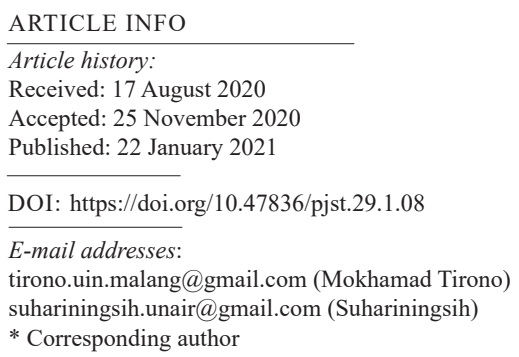

\section{INTRODUCTION}

Bacteria often form biofilms on the surfaces of medical devices such as venous catheters, breast implants, pacemakers, and others (Lazăr \& Chifiriuc, 2010). Unfortunately, materials used in these medical devices generally cannot withstand high temperature. 
Moreover, biofilms have proven to be very resistant to several types of antibiotics and chemical disinfectants (Eriksson, 2011), making it difficult to inhibit their growth. Therefore, a right sterilization technique that can reduce the number of bacteria quickly but also does not cause heat to the materials of medical devices is highly needed, such as sterilization using high-intensity electric fields (Ramaswamy et al., 2019; Bonetta et al., 2014). In fact, the interaction between high-intensity electric fields with bacteria causes irreversible electroporation to the cell membrane (Miklavčič, 2017), which in turn induces bacterial death (Rosin \& Kurrasch, 2018). However, exposure to these high-intensity electric fields can harm the organs of the human body or other living things around the exposure if the security is less than optimal. Negative effects that can occur are complaints on the face (Skulberg et al., 2001), decreased red blood cells (Di et al., 2018), reduction in sperm count and motility, damage to Deoxyribose Nucleic Acid (DNA), and oxidative stress (Aslankoc et al., 2018).

To reduce the negative impacts of sterilization on medical devices and human body, sterilization using low-intensity electric fields can be done, particularly for one that does not require short period of time in its treatment process. This, therefore, requires data on the lowest electric field intensity and treatment time for inactivating bacteria as well as data on a deactivation mechanism for their development. For the effectiveness of its implementation, it requires mathematical modeling that can predict the lowest electric field intensity and treatment time for the inactivation of the bacteria that make up the biofilms, and that can be used to explain the mechanism of deactivation.

Several studies have been conducted on mathematical modeling of the use of electric fields. Previously, a study was conducted on mathematical modeling of the use of electric fields to predict the growth of Escherichia coli bacteria in carrot juice (Singh et al., 2017). There has also been another modeling to predict the effect of the electric field on changes in spore morphology in Bacillus atrophaeus bacteria (Qiu et al., 2014), ion transport inside and outside the soft layer in Gram-positive bacteria (Moran et al., 2018), and changes in the bacterial pore radius (Mescia et al., 2019). Specifically, a model developed by Singh et al. (2017) still used a high electric field intensity at 9-21 kV/cm, while a model developed by Qiu et al. (2014), Moran et al. (2018), and Mescia et al. (2019) had not reported a reduction in the number of bacteria that occured. Therefore, modeling to predict the lowest intensity in order to reduce the number of bacteria is highly needed.

In this study, a mathematical model developed from the Pockels effect and the Weibull distribution has been formulated. The present study aims at predicting the lowest electric field intensity and treatment time for inactivating bacteria and explaining the deactivation mechanism. 


\section{METHODS}

\section{Theory}

This study used an electric field generated using parallel plates, so the field intensity between the plates is (Equation 1):

$$
\boldsymbol{E}=\frac{\Delta \boldsymbol{V}}{d}
$$

where $\boldsymbol{E}$ is the electric field between parallel plates, $d$ is the distance between the plates, and $\Delta V$ is the potential difference between the plates. Bacterial cell membranes, especially those in the lipid bilayer, have anisotropic (Pogozheva et al., 2013; Huh et al., 2016) and electro-optical properties (Bunin et al., 2005), so when they interact with an external electric field, they experience a change in the refractive index (Eismann, 2012), which satisfies the Equation 2:

$$
n(\boldsymbol{E})=n-1 / 2 r n^{3} \boldsymbol{E}
$$

where $r$ is called the Pockel coefficient, $n$ and $n(\boldsymbol{E})$ are the refractive index before and after being subjected to an electric field, respectively, and $\boldsymbol{E}$ is the electric field.

Bacteria, especially lipid bilayers, are media that tend to be uniaxial (Galdiero et al., 2013), so when interacting with electric fields their refractive index is expressed as $n_{x}=$ $n_{y}=n_{o}$ and $n_{z}=n_{e}$ (Eismann, 2012). If the electric field points to the z-axis, then $\boldsymbol{E}$ ( $x, y$, $z)=(0,0, \boldsymbol{E})$. Therefore, the ellipsoid refractive index is expressed as Equation 3 and 4 (Eismann, 2012), i.e.:

$$
\begin{aligned}
& n_{o}(E)=n_{o}(0)-\frac{1}{2} n_{o}^{3} r_{13} \boldsymbol{E} \\
& n_{e}(E)=n_{e}(0)-\frac{1}{2} n_{e}^{3} r_{33} \boldsymbol{E}
\end{aligned}
$$

For example, the electric field is changed by $\Delta E$, so the extraordinary refractive index changes that occur is (Equation 5):

$$
\Delta n_{e}=-\frac{1}{2} n_{e}^{3} r_{33} \Delta \boldsymbol{E}
$$

where $\Delta n_{e}$ is the change of the refractive index in $z$ axis.

\section{Diffusion of Water and Ions in the Cell Membrane}

Exposure to the electric field in bacteria triggers changes in cell membrane permeability (Sweeney et al., 2018). Increased permeability causes changes in the diffusion of water and ions in the cell membrane (Kakorin \& Neumann, 2002) expressed as Equation 6: 


$$
\Delta n_{e}=-\Delta f_{W} n_{e}+\Delta f_{W} n_{a}
$$

The substitution of Equation 5 with 6 is done by changing the electric field from $E=$ 0 to $\boldsymbol{E}$, and then it is obtained as Equation 7:

$$
\Delta f_{W}=\frac{1}{2} \frac{n_{e}^{3} r}{n_{e}-n_{a}} \boldsymbol{E}
$$

where $\Delta f_{W}=f_{W}(E)-f_{W}(0)$ is the fraction of increasing volume of water and ion flow in the membrane, and $n_{a}$ is the refractive index of water.

\section{Cell Membrane Conductivity}

Increased ion flow through the cell membrane will cause an increase in cell conductivity. The conductivity of the cell membrane is determined using the conductance of the permeable pore $(m)$, assuming that the pore radius is $R$ (Pavlin et al., 2005), so the conductivity of the cell membrane is obtained as Equation 8:

$$
\sigma=m \pi R^{2} \frac{\sigma_{s}}{d_{m}}=S_{\text {por }} \frac{\sigma_{s}}{d_{m}}
$$

where $\sigma_{s}$ is the conductivity of the pore, $d_{m}$ is the thickness of the cell membrane, and $S_{p o r}$ is the surface area of all conducting pores. Changes in the diffusion of water and ions that pass through the cell membrane change the conductivity of the pores in the cell membrane, which becomes Equation 9:

$$
\sigma_{s}(E)=\sigma_{s}(0)+\Delta \sigma_{s}
$$

where $\sigma_{s}(0)$ is the pore conductivity at condition $\boldsymbol{E}=0$, while $\sigma_{s}(E)$ is the pore conductivity at the electric field condition $\boldsymbol{E}$. Thus, the conductivity of the cell membrane, when subjected to an electric field $\boldsymbol{E}$, is (Equation 10)

$$
\sigma(E)=\sigma\left(1+\frac{1}{2} \frac{n_{e}^{3} r}{n_{e}-n_{a}} m_{p o r} \boldsymbol{E}\right)
$$

where $m_{p o r}$ is the number of pores in a bacterial cell. As a result of the increased conductivity of cell membranes, membrane damage occurs, which causes bacterial death (Pagán \& Mackey, 2000).

\section{The Reduction of the Number of Bacteria}

The reduction in the number of bacteria in the logarithmic form is determined by modifying the Weibull distribution equation, thus obtaining the Equation 11 (Puértolas et al., 2009): 


$$
\log \frac{N(t)}{N_{o}}=-\left(\frac{W}{\delta}\right)^{\rho}
$$

where the $\rho$ value is the shape parameter. $N(t)$ is the number of bacteria that remain after exposure during $t, N_{o}$ is the number of bacteria before exposure, and $W$ is the electrical energy used.

The amount of electrical energy $W$ needed to deactivate bacteria (Monfort et al., 2012) is (Equation 12):

$$
W=\sigma(E) \boldsymbol{E}^{2} t
$$

The scale parameter $(\delta)$ is determined from a model based on the Gompertz function (Maria et al., 2011), which is expressed as Equation 13:

$$
\delta=b e^{-e^{c(E-d)}}
$$

where $\delta$ value represents the specific energy to do first inactivation, $\boldsymbol{E}$ is the electric field strength, $b, c$ and $d$ are the model parameters.

The reduction in the number of bacteria is determined by substituting Equation 10, 12, and 13 into Equation 11, to obtain Equation 14:

$$
\log \frac{N(t)}{N_{o}}=\left(\frac{\sigma\left(1+\frac{1}{2}\left(\frac{n_{e}^{3} r}{n_{e}-n_{a}}\right) \boldsymbol{E} m_{\text {por }}\right) \boldsymbol{E}^{2} t}{\delta}\right)^{\rho}
$$

where $\rho$ value accounts for upward concavity of a survival curve $(\rho<1)$, a linear survival curve $(\rho=1)$, and downward concavity $(\rho>1)$ (Puértolas et al., 2009). Equation 14 shows that the electric field intensity and treatment time affect the reduction in the number of bacteria.

\section{Biofilm Growth}

Study samples were Pseudomonas aeruginosa and Staphylococcus epidermidis bacteria grown on catheters. Pure isolates from the bacteria Pseudomonas aeruginosa and Staphylococcus epidermidis were each inserted into a tube containing $50 \mathrm{ml}$ of sterile liquid Nutrient Broth (NB) and incubated in an incubator for 24 hours at a temperature of $37^{\circ} \mathrm{C}$. A clean and sterile cut of the catheter was inserted into a tube that was covered with Pseudomonas aeruginosa and Staphylococcus epidermidis bacteria. The tube containing the bacteria was incubated again for 3 days at a temperature of $37^{\circ} \mathrm{C}$ and shaken at $100 \mathrm{rpm}$. 


\section{Treatment Process}

The biofilm treatment was carried out using a pulsed electric field with an intensity of 2.0-4.0 kV/cm and a pulse width of $50 \mu$ s for 5-25 minutes. Moreover, the space around the treatment area was sterilized, the ambient temperature was set to around $28^{\circ} \mathrm{C}$, and the humidity was at around $70 \%$. The treatment process for both control and treatment groups was repeated five times..

\section{Bacterial Release from Biofilms}

The taking of the catheter pieces that had been overgrown with biofilms was carried out using sterile tweezers, in both control and treatment groups, so as not to contaminate other bacteria. Before being treated and diluted, the sample was cleaned with purified water that had been sterilized to release planktonic cells. After being treated, the catheter piece was inserted into a test tube containing $10 \mathrm{ml}$ of $0.9 \% \mathrm{NaCl}$, which was then added with 0.5 gram glass beads and vibrated using a vertex for 2 minutes to release the bacterial cells (Krysinski et al., 1992). After the bacteria were released, then $1.0 \mathrm{ml}$ was taken to do the dilution.

\section{Calculation of the Number of Colonies}

Before doing the calculation, at first, a measure of the bacterial culture that had been released from the catheter was carried out. Dilution was done by taking $1.0 \mathrm{ml}$ of bacterial culture and placing it in a bottle containing $9.0 \mathrm{ml}$ of sterile distilled water, so the volume became $10 \mathrm{ml}$. The bacterial culture from the dilution was taken again as much as $1.0 \mathrm{ml}$ and put into a bottle containing $9.0 \mathrm{ml}$ sterile distilled water, so the volume was $10 \mathrm{ml}$. The dilution was repeated according to the calculation requirements. After the dilution process, a culture of $1.0 \mathrm{ml}$ was taken and then sprinkled on a petri dish that had been given liquid plate count agar (PCA) media. Next, the Petri dishes that had been cultured were incubated in an incubator for 24 hours at $37^{\circ} \mathrm{C}$. After the colony was formed, the colony count was calculated using a Colony Counter.

\section{Variable Values in Modeling}

The intensity of the electric field used to treat was $2.0-4.0 \mathrm{kV} / \mathrm{cm}$, while the time of treatment was 5-25 minutes. The conductivity value $(\sigma)$ of Pseudomonas aeruginosa bacterial cells was determined by referring to the conductivity of Escherichia coli (Gramnegative) bacteria, which was at a concentration of $1 \times 10^{9}-4 \times 10^{9} \mathrm{cfu} / \mathrm{ml}$; the conductivity was $2 \times 10^{-6}-1.4 \times 10^{-5} \mathrm{mho} / \mathrm{m}$. Meanwhile, the conductivity value $(\sigma)$ of Staphylococcus epidermidis refers to the conductivity of Bacillus subtilis (Gram-positive), which was at a concentration of $1 \times 10^{8}-8 \times 10^{8} \mathrm{cfu} / \mathrm{ml}$; the conductivity was $0.5 \times 10^{-5}-5 \times 10^{-5} \mathrm{mho} / \mathrm{m}$ (Fangxia et al., 2013). Pockels coefficient $r$ of the cell membrane was $2.6 \mathrm{pm} / \mathrm{V}$ (Hajj et 
al., 2009), lipid refractive index $n_{e}$ was 1.384 , water refractive index $n_{a}$ was 1.342 , and the number of pores was given the values as expressed by Martinac et al. (2008). Moreover, the $\rho$ value was 0.75 , while the $\delta$ valuewas obtained from Equation 13 by giving a $d$ value depending on the shape and size of the bacteria and $\boldsymbol{E}$ was the electric field strength used for inactivation (Puértolas et al., 2009).

\section{RESULTS}

\section{Electric Field Effect}

Pseudomonas aeruginosa bacteria are Gram-negative, motile, and rod-shaped about 1-5 $\mu \mathrm{m}$ long and 0.5-1.0 $\mu \mathrm{m}$ wide (Diggle \& Whiteley, 2020), while Gram-positive Staphylococcus epidermidis bacteria are cocci shaped and 0.5-1.5 $\mu \mathrm{m}$ in diameter. The reduction in the number of Pseudomonas aeruginosa bacteria in the log due to treatment with an electric field intensity of $2.0-4.0 \mathrm{kV} / \mathrm{cm}$ is shown in Figure 1, where the negative sign indicates a reduction. Figure 1 shows that the treatment using an electric field with an intensity of $2.0-3.25 \mathrm{kV} / \mathrm{cm}$ formed a line close to horizontal, which means that the reduction in the number of bacteria is relatively small, so it is not effective to be used in bacterial inactivation. Meanwhile, line deflection occured on treatment with intensity from $3.5 \mathrm{kV} /$ $\mathrm{cm}$ to $3.75 \mathrm{kV} / \mathrm{cm}$, which means that the decrease in the number of bacteria increases or is at the threshold for irreversible electroporation. The line decreased when there was a treatementwith an intensity of $4.0 \mathrm{kV} / \mathrm{cm}$, so it is assumed that irreversible electroporation has occurred.

Figure 1 shows that the modeling result graph has the same pattern as the experimental result graph but has a R-squared of 0.923 for the 10 -minute treatment time and 0.961 for the 25-minute treatment time. The modeling graph was obtained by entering the scale parameter values that changed along with changes in the electric field intensity as shown

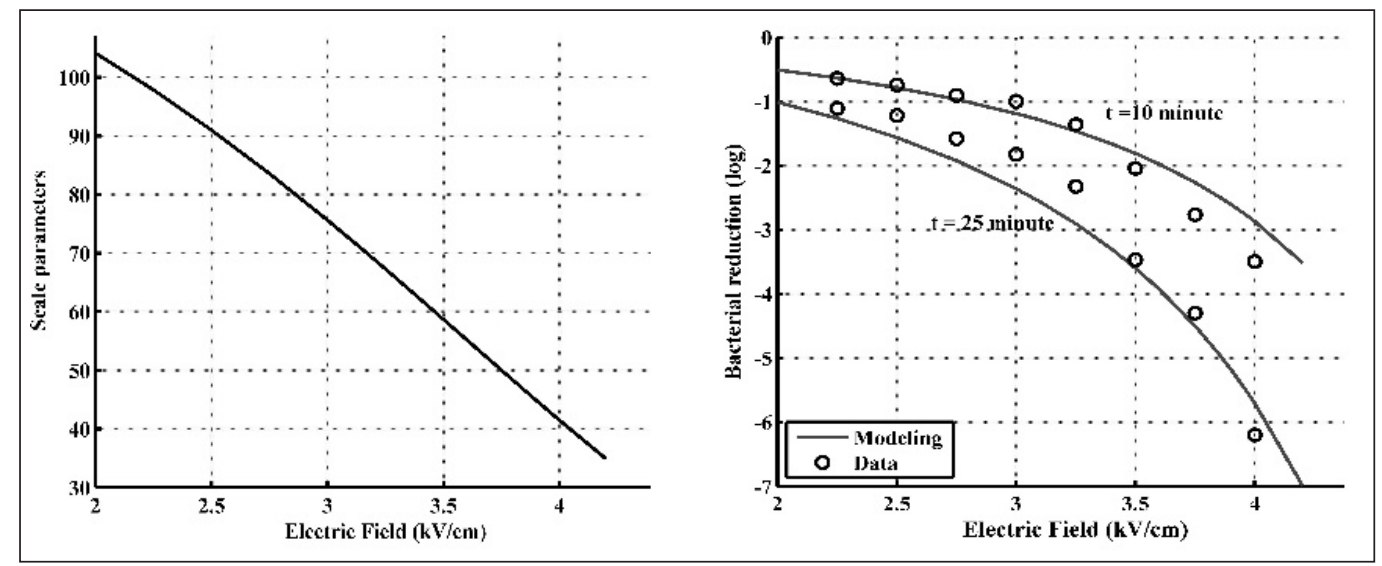

Figure 1. The reduction in the number of Pseudomonas aeruginosa bacteria after being treated with an electric field 


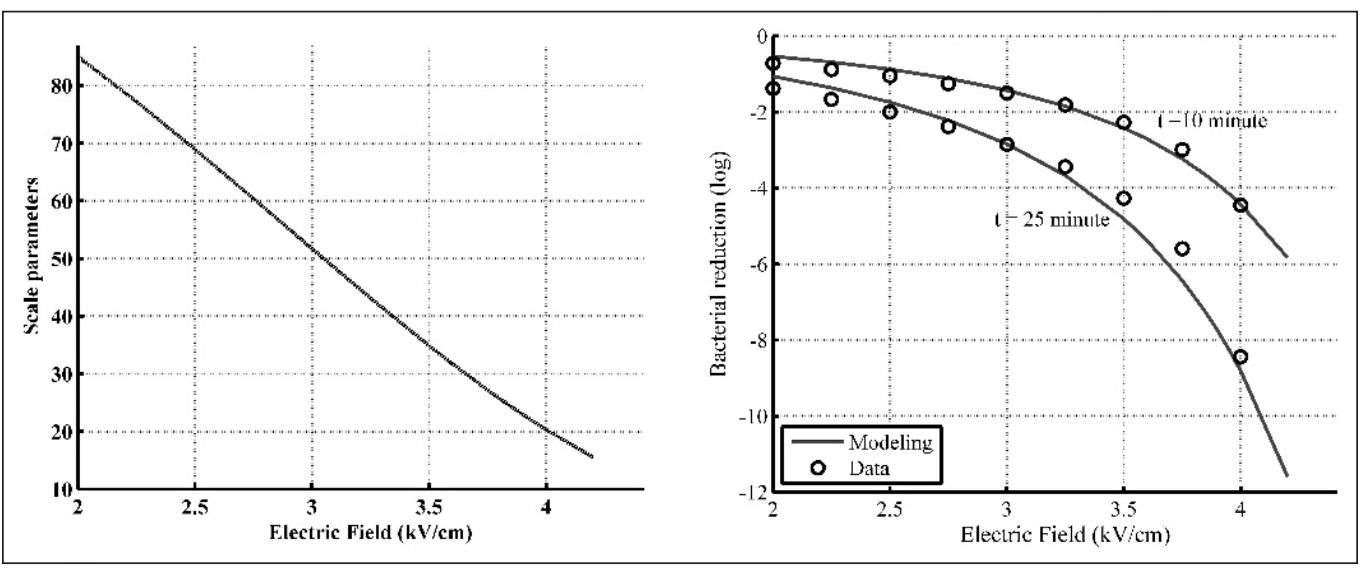

Figure 2. The reduction in the number of Staphylococcus epidermidis bacteria after being treated with an electric field

in Figure 1. Changes in scale parameters are identical to those reported by Puértolas et al. (2009), suggesting that the higher the intensity of electric field used, the lower the values of scale parameters. Scale parameters are considered as a measure of the resistance of bacteria to treatment using an electric field (Alvarez et al., 2003), which also depends on the temperature and $\mathrm{PH}$ of the medium (Huang et al., 2012). The constants $b, c$, and $d$ from Equation 13, which were 150, 0.63 and 3.6, respectively, while the value of $E$ changed according to changes in the intensity of the electric field used.

Staphylococcus epidermidis bacteria treated using an electric field with an intensity of $2.0-4.0 \mathrm{kV} / \mathrm{cm}$ experience a reduction in the number of bacteria, graphically the reduction is shown in Figure 2. The graph shows that biofilms treated using an electric field intensity of $2.0-3.25 \mathrm{kV} / \mathrm{cm}$ had a horizontal line because it was still below the irreversible electroporation threshold. The graph goes down when treated using an electric field with an intensity of $3.5-3.75 \mathrm{kV} / \mathrm{cm}$, which means that the reduction in the number of bacteria increases because the bacterial cell membrane is at the threshold for irreversible electroporation. The reduction in the number of bacteria becomes large with a treatment using an electric field with an intensity of $4.0 \mathrm{kV} / \mathrm{cm}$ because the bacterial cell membrane had undergone irreversible electroporation.

Figure 2 shows a similar pattern with the graph of the modeling result and the experimental result, which means that a mathematical model can be used to predict the reduction in the number of bacteria on the biofilms from Staphylococcus epidermidis. The modeling result graph had a R-squared of 0.975 when given the 10-minute treatment and 0.980 when the treatment time was 25 minutes. The modeling graph was obtained by giving the scale parameter values as shown in Figure 2. The constants $b, c$, and $d$ from Equation 13 , which were $150,0.63$, and 2.9 , respectively, while the $E$ value changed according to changes in the intensity of the electric field used. 


\section{Treatment Time Effect}

When the electric field used is different, the impact on bacteria is also different, which also impacts on the difference in the the reduction in the number of bacteria that occurs. Figure 3 is the effect of treatment time on reducing the number of Pseudomonas aeruginosa bacteria, and Figure 4 is the effect of treatment time on reducing the number of Staphylococcus epidermidis bacteria. The two graphs show that the treatment using an electric field with

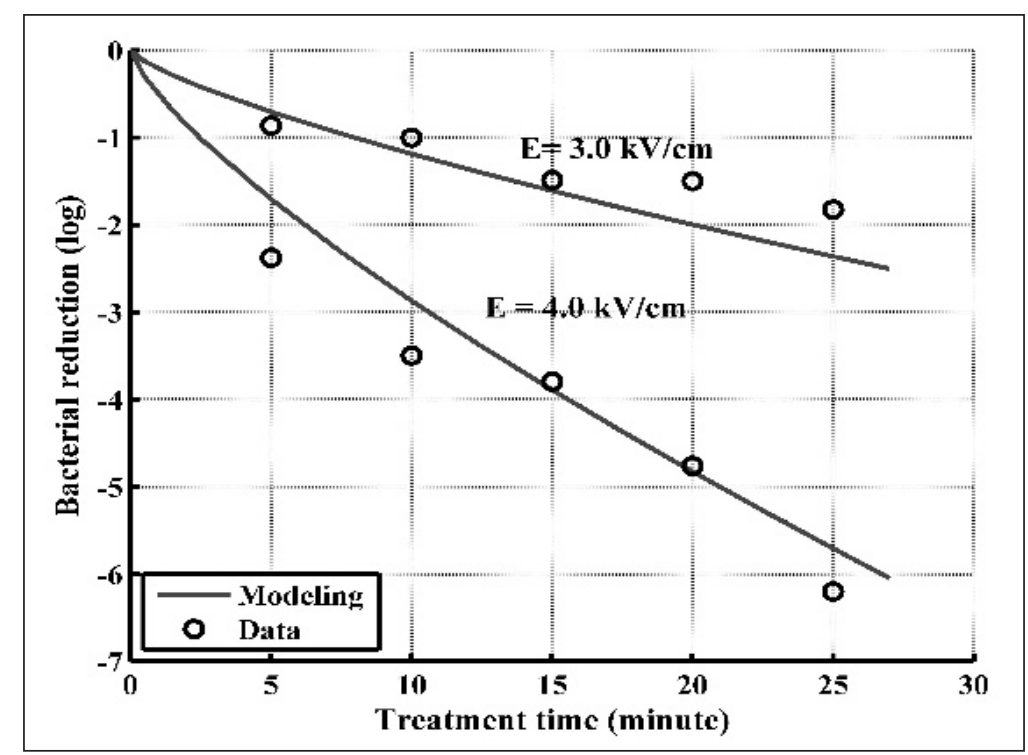

Figure 3. Reduction in the number of Pseudomonas aeruginosa due to changes in the treatment time

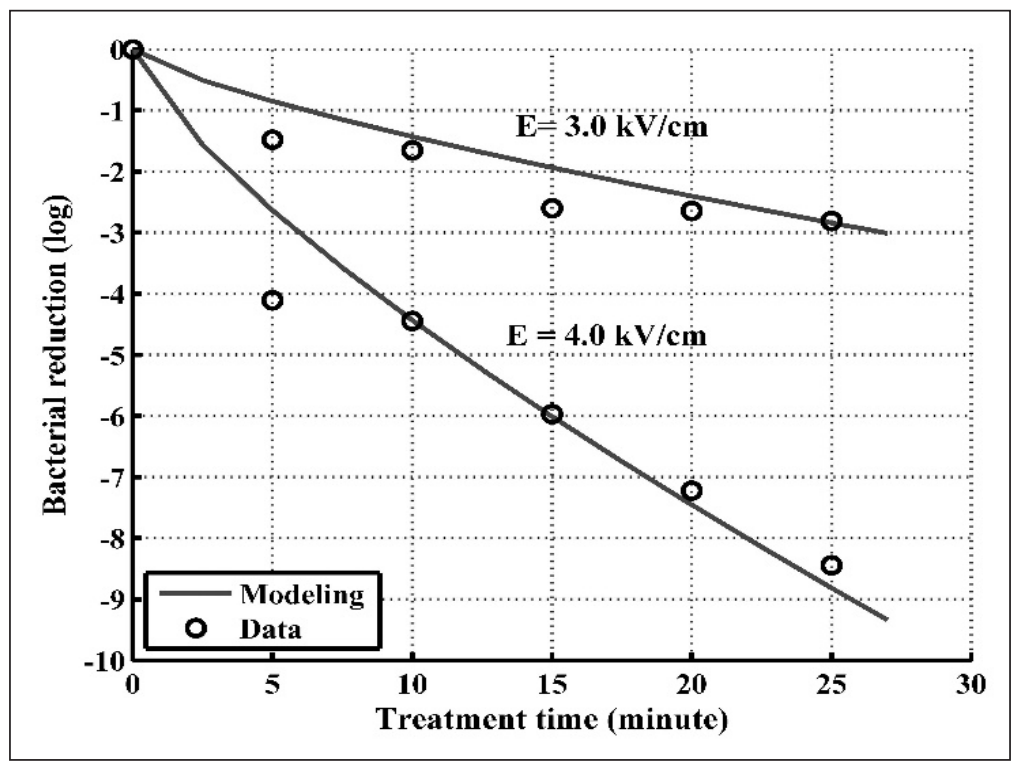

Figure 4. Reduction in the number of Staphylococcus epidermidis due to changes in the treatment time 
an intensity of $3.0 \mathrm{kV} / \mathrm{cm}$ had a small effect on reducing the number of bacteria because it was still below the irreversible electroporation threshold. Meanwhile, the treatment using an electric field with an intensity of $4.0 \mathrm{kV} / \mathrm{cm}$ had a significant effect on reducing the number of bacteria because irreversible electroporation had occurred.

Figures 3 and 4 show the similarity of the pattern between the graph of the modeling result and the experimental result, which means that the mathematical model can be used to predict the decrease in the number of bacteria on biofilms from Pseudomonas aeruginosa and Staphylococcus epidermidis due to changes in treatment time. For Pseudomonas aeruginosa, the modeling R-squared were 0.991 and 0.999 for the electric field intensity of $3.0 \mathrm{kV} / \mathrm{cm}$ and $4.0 \mathrm{kV} / \mathrm{cm}$, respectively, while for Staphylococcus epidermidis bacteria the modelling R-squared were 0.894 and 0.946 accordingly.

\section{DISCUSSION}

The outermost part of a bacterial cell is the plasma membrane, which is a barrier between the inside and outside of the cell, so it has a very important role (Silhavy et al., 2010). The cell membrane has a positive outer and inner negative charge, thus forming a potential difference between them (Gottenbos, 2001), which is called the transmembrane potential. In fact, the transmembrane potential becomes an obstacle for the circulation of substances from outside to inside or vice versa. However, in the cell membrane, there are ion channels that control the flow of solutes into the cells and organelles, playing an important role in maintaining homeostasis (Hohle et al., 2011). The interaction of the external electric field with the cell causes a shift in charge, especially the cell membrane, so the cell experiences electronic polarization. Electronic polarization itself causes a change in the refractive index of a cell, resulting in permeability changes. Due to the electrooptic nature of the cell membrane which tends to be anisotropic, the changes satisfy the Equation 3 and 4. Moreover, increased permeability, causing the flow of water and ions that pass through the cell membrane, also increases because the pore diameter enlarges (Kotnik et al., 2019), as formulated in Equation 7. Increased ion flow causes an increase in cell membrane conductivity (Pliquett et al., 2007), as in Equation 10. Furtermore, the part of the cell membrane with increased conductivity will cause damage (Silve et al., 2016), so the bacteria are inactive. Treatment using an electric field with an intensity of $2.0-3.25 \mathrm{kV} / \mathrm{cm}$ makes the conductivity of the cell membrane increases insignificantly, so the reduction in the number of bacteria is still low. In addition to the increase in conductivity, the interaction between the electric field and bacteria causes the transmembrane voltage to increase, where the increase satisfies the equation $\Delta \psi=1.5 \boldsymbol{E} R_{a} \cos \theta$ (Pavlin et al., 2005) where $R_{a}$ is the cell radius and $\boldsymbol{E}$ is the electric field. When treated using an electric field with an intensity of $3.5-3.75 \mathrm{kV} / \mathrm{cm}$, the channel porosity radius and transmembrane voltage are at the threshold of irreversible electroporation, so the reduction in the number of bacteria increases, and its visibility is 
shown in Figures 5 and 6. Part A is the condition of the biofilms before being treated, while part $\mathrm{B}$ is the condition after being treated, so part A shows the adhering bacteria covered with carbohydrates, while part B has a few bacteria. Treating the bacteria using an electric field with an intensity of $4.0 \mathrm{kV} / \mathrm{cm}$ makes the conductivity of the cell membrane increase sharply, so the amount of reduction in bacteria is very large. Also, treated the bacteria using an electric field with an intensity of $4.0 \mathrm{kV} / \mathrm{cm}$ makes the conductivity of the cell membrane increase sharply, resulting in a potential breakdown in the cell membrane (Akinlaja \& Sachs, 1998). Therefore, treatment using high-intensity electric fields requires a very short amount of time.

This modeling is effective for predicting the reduction in the number of bacteria due to treatment using low electric field intensity. The modeling error when compared with experimental data was at an average of $8.54 \%$ for Pseudomonas aeruginosa and $7.82 \%$ for Staphylococcus epidermidis. The error will increase when electric field intensities above $4.5 \mathrm{kV} / \mathrm{cm}$ is applied. The modeling conducted by Singh et al. (2017) has a lower error,

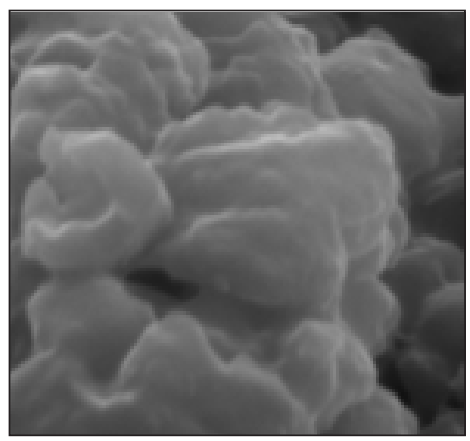

(a)

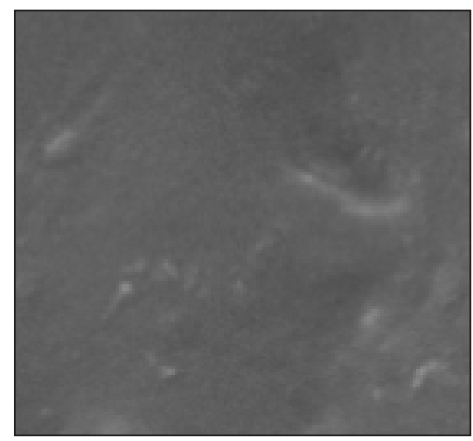

(b)

Figure 5. Biofilms from Pseudomonas aeruginosa bacteria: (a) before treatment; and (b) after treatment with an electric field intensity of $3.5 \mathrm{kV} / \mathrm{cm}$ for 25 minutes. Magnification of $10,000 \mathrm{x}$

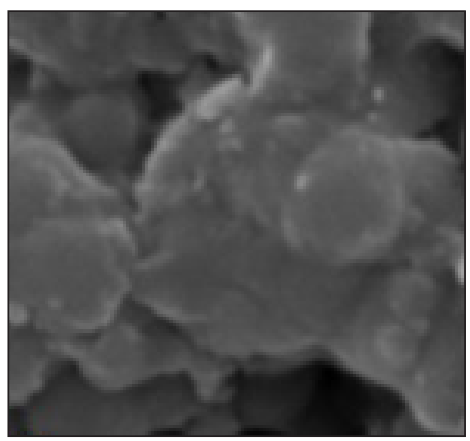

(a)

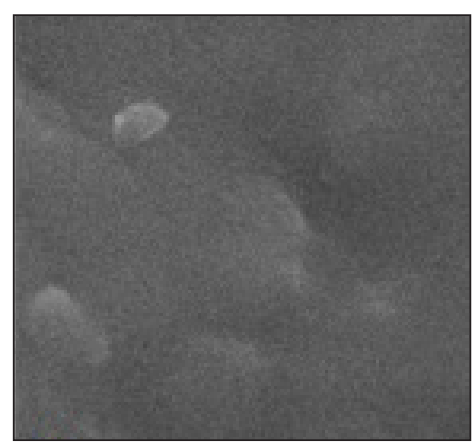

(b)

Figure 6. Biofilms from Staphylococcus epidermidis bacteria: (a) before treatment; and (b) after treatment with an electric field intensity of $3.5 \mathrm{kV} / \mathrm{cm}$ for 25 minutes. Magnification of $10,000 \mathrm{x}$ 
which is less than $5 \%$ with an electric field intensity of $9-21 \mathrm{kV} / \mathrm{cm}$, but its application has not been reported at lower electric field intensities. Similar modeling was also carried out by Peleg (2017) by giving a treatment using an electric field of $8.0-20.0 \mathrm{kV} / \mathrm{cm}$.

\section{CONCLUSION}

This study discusses the deactivation model of bacteria that have formed biofilms using the electrooptical principle combined with the Weibell distribution equation to predict a bacterial reduction. The model is used to predict the reduction in the number of bacteria due to treatment using an electric field at a low intensity. The study has found a threshold for irreversible electroporation on biofilms from Pseudomonas aeruginosa and Staphylococcus epidermidis bacteria at an electric field intensity of $3.5 \mathrm{kV} / \mathrm{cm}$ and $3.75 \mathrm{kV} / \mathrm{cm}$, respectively. In addition, the time of the treatment has an effect if the treatment uses an electric field with an intensity above the threshold, otherwise it does not affect. Also, the interaction of the electric field with bacteria causes electronic polarization, thereby lowering the refractive index and increasing the permeability of the cell membrane. The high permeability of the cell membrane causes the flow of water and ions through the cell membrane to increase, so the conductivity of the cell membrane increases. The high conductivity causes damage to the cell membrane, so the bacteria die.

\section{ACKNOWLEDGMENT}

This research was carried out on the financial assistance from the Directorate of Islamic Higher eEucation, Indonesian Ministry of Religious Affairs. Therefore, we thank the Minister of Religious Affairs along with his staff. We also thank the research and community service institution of State Islamic Universities of Maulana Malik Ibrahim Malang.

\section{REFERENCES}

Akinlaja, J., \& Sachs, F. (1998). The breakdown of cell membranes by electrical and mechanical stress. Biophysical Journal, 75(1), 247-254. doi: 10.1016/S0006-3495(98)77511-3

Alvarez, I., Pagan, R., Condon, S., \& Raso, J. (2003). The influence of process parameters for the inactivation of Listeria monocyogenes by pulsed electric fields. International Journal of Food Microbiology, 87(1-2), 87-95. doi: https://doi.org/10.1016/S0168-1605(03)00056-4

Aslankoc, R., Gumral, N., Saygin, M., Senol, N., Asci, H., Cankara, F. N., \& Comlekci, F. (2018). The impact of electric fields on testis physiopathology, sperm parameters and DNA integrity - The role of resveratrol. Andrologia, 50(4), 1-11. doi: 10.1111/and.12971

Bonetta, S., Bonetta, S., Bellero, M., Pizzichemi, M., \& Carraro, E. (2014). Inactivation of Escherichia coli and Staphylococcus aureus by pulsed electric fields increases with higher bacterial population and with agitation of liquid medium. Journal of Food Protection, 77(7), 1219-1223. doi: 10.4315/0362-028X. JFP-13-487 
Bunin, V. D., Ignatov, O. V., Guliy, O. I ., Zaitseva, I. S., Neil, D. O., \& Ivnitskii, D. (2005). The electrooptical parameters of suspensions of Escherichia coli XL-1 cells interacting with helper phage M13K07. Microbiology, 74(2), 164-168.

Di, G., Gu, X., Lin, Q., Wu, S., \& Kim, H. B. (2018). A comparative study on effects of static electric field and power frequency electric field on hematology in mice. Ecotoxicology and Environmental Safety, 166(September), 109-115. doi: 10.1016/j.ecoenv.2018.09.071

Diggle, S. P., \& Whiteley, M. (2020). Microbe profile: Pseudomonas aeruginosa: Opportunistic pathogen and lab rat. Microbiology, 166(1), 30-33. doi: 10.1099/mic.0.000860

Eismann, M. T. (2012). Optical radiation and matter. In M. T. Eismann (Ed.), Hyperspectral remote sensing (pp. 37-82). Washington, USA: SPIE Press. doi: 10.1117/3.899758.ch2

Eriksson, J. (2011). Biofilm growth in strong electric fields (Master Thesis). KTH Royal Institute of Technology, Sweden.

Fangxia, S., Miaomiao, T., Hong, X., Zhencheng, X., \& Maosheng, Y. (2013). Development of a novel conductance-based technology for. Environmental Chemistry, 58(4), 440-448. doi: 10.1007/s11434012-5621-1

Galdiero, S., Falanga, A., Cantisani, M., Vitiello, M., Morelli, G., \& Galdiero, M. (2013). Peptide-lipid interactions: experiments and applications. International Journal of Molecular Sciences, 14(9), 1875818789. doi: 10.3390/ijms140918758

Gottenbos, B. (2001). Antimicrobial effects of positively charged surfaces on adhering Gram-positive and Gram-negative bacteria. Journal of Antimicrobial Chemotherapy, 48(1), 7-13. doi: 10.1093/jac/48.1.7

Hajj, B., Pioufle, B. L., Osaki, T., \& Suzuki, H. (2009). Electro-optical imaging microscopy of dyedoped artificial lipidic membranes. Biophysical Journal, 97(December), 2913-2921. doi: 10.1016/j. bpj.2009.08.055

Hohle, T. H., Franck, W. L., Stacey, G., \& O’Brian, M. R. (2011). Bacterial outer membrane channel for divalent metal ion acquisition. Proceedings of the National Academy of Sciences of the United States of America, 108(37), 15390-15395. doi: 10.1073/pnas.1110137108

Huang, K.,Tian, H., Gai, L., \& Wang, J. (2012). A review of kinetic models for inactivating microorganisms and enzymes by pulsed electric field processing. Journal of Food Engineering, 111, 191-207. doi:10.1016/j. jfoodeng.2012.02.007

Huh, K., Oh, D., Son, S. Y., Yoo, H. J., Song, B., Cho, D. I. D., ... \& Kim, S. J. (2016). Laminar flow assisted anisotropic bacteria absorption for chemotaxis delivery of bacteria-attached microparticle. Micro and Nano Systems Letters, 4(1), 1-9. doi: 10.1186/s40486-016-0026-6

Kakorin, S., \& Neumann, E. (2002). Electrooptical relaxation spectrometry of membrane electroporation in lipid vesicles. A: Physicochemical and Engineering Aspects, 209(2-3), 147-165. doi: https://doi.org/10.1016/ S0927-7757(02)00176-0

Kotnik, T., Rems, L., Tarek, M., \& Miklavčič, D. (2019). Membrane electroporation and electropermeabilization: Mechanisms and Models. Annual Review of Biophysics, 48(1), 63-91. doi: 10.1146/annurevbiophys-052118-115451 
Krysinski, E. P., Brown, L. J., \& Marchisello, T. J. (1992). Effect of cleaners and sanitizers on Listeria monocytogenes attached to product contact surfaces. Journal of Food Protection, 55(4), 246-251. doi: https://doi.org/10.4315/0362-028X-55.4.246

Lazăr, V., \& Chifiriuc, M. C. (2010). Medical significance and new therapeutical strategies for biofilm associated infections. Roumanian Archives of Microbiology and Immunology, 69(3), 125-138

Maria, M. G., Fatima, A. M., Teresa, R. S. B., \& Cristina, L. M. S. (2011). On the use of the gompertz model to predict microbial thermal inactivation under isothermal and non-isothermal conditions. Food Engineering Reviews, 3, 17-25. doi: 10.1007/s12393-010-9032-2

Martinac, B., Saimi, Y., \& Kung, C. (2008). Ion channels in microbes. Physiological Reviews, 88(4), 14491490. doi: 10.1152/physrev.00005.2008.Ion

Mescia, L., Chiapperino, M. A., Bia, P., Lamacchia, C. M., Gielis, J., \& Caratelli, D. (2019, June 17-20). Multiphysics Modelling of Membrane Electroporation in Irregularly Shaped Cells. In 2019 Photonics \& Electromagnetics Research Symposium-Spring (PIERS-Spring) (pp. 2992-2998). Rome, Italy. doi: 10.1109/PIERS-Spring46901.2019.9017428

Miklavčič, D. (2017). Handbook of electroporation. Cham, Switzerland: Springer International Publishing. doi: https://doi.org/10.1007/978-3-319-32886-7

Monfort, S., Saldaña, G., Condón, S., Raso, J., \& Álvarez, I. (2012). Inactivation of Salmonella spp. in liquid whole egg using pulsed electric fields, heat, and additives. Food Microbiology, 30(2), 393-399. doi: 10.1016/j.fm.2012.01.004

Moran, J. L., Dingari, N. N., Garcia, P. A., \& Buie, C. R. (2018). Numerical study of the effect of soft layer properties on bacterial electroporation. Bioelectrochemistry, 123, 261-272. doi: 10.1016/j.bioelechem. 2017.09.004

Pagán, R., \& Mackey, B. (2000). Relationship between membrane damage and cell death in pressure-treated Escherichia coli cells: differences between exponential-and stationary-phase cells and variation among strains. Applied and Environmental Microbiology, 66(7), 2829-2834. doi: 10.1128/AEM.66.7.28292834.2000

Pavlin, M., Rebers, M., Pucihar, G., Hart, F. X., \& Magjarevic, R. (2005) Effect of cell electroporation on the conductivity of a cell suspension. Biophysical Journal, 88(June), 4378-4390. doi: 10.1529/ biophysj.104.048975

Peleg, M. (2017). Modeling microbial inactivation by pulsed electric field. In D. Miklavcic (Ed.), Handbook of Electroporation (pp.1269-1286). Cham, Swetzerland: Springer International Publishing. doi: 10.1007/9783-319-32886-7 43

Pliquett, U., Joshi, R. P., Sridhara, V., \& Schoenbach, K. H. (2007). High electrical field effects on cell membranes. Bioelectrochemistry, 70(2), 275-282. doi: 10.1016/j.bioelechem.2006.10.004

Pogozheva, I. D., Tristram-Nagle, S., Mosberg, H. I., \& Lomize, A. L. (2013). Structural adaptations of proteins to different biological membranes. Biochimica et Biophysica Acta (BBA)-Biomembranes, 1828(11), 25922608. doi: 10.1016/j.bbamem.2013.06.023 
Puértolas, E., López, N., Condón, S., Raso, J., \& Álvarez, I. (2009). Pulsed electric fields inactivation of wine spoilage yeast and bacteria. International Journal of Food Microbiology, 130(1), 49-55. doi: 10.1016/j. ijfoodmicro.2008.12.035

Qiu, X., Lee, Y. T., \& Yung, P. T. (2014, August 26-30). A bacterial spore model of pulsed electric fields on spore morphology change revealed by simulation and SEM. In 2014 36th Annual International Conference of the IEEE Engineering in Medicine and Biology Society (pp. 6822-6825). Chicago, IL, USA. doi: 10.1109/EMBC.2014.6945195

Ramaswamy, R., Ramachandran, R. P., \& Gowrisree, V. (2019). High voltage pulsed electric field application using titanium electrodes for bacterial inactivation in unpurified water. Japan Journal of Food Engineering, 20(2), 63-70. doi: 10.11301/jsfe.19546

Rosin, J. M., \& Kurrasch, D. M. (2018). In utero electroporation induces cell death and alters embryonic microglia morphology and expression signatures in the developing hypothalamus. Journal of Neuroinflammation, 15(1), 1-15. doi: 10.1186/s12974-018-1213-6

Silhavy, T. J., Kahne, D., \& Walker, S. (2010). The bacterial cell envelope. In T. J. Silhavy, D. Kahne \& S. Walker (Eds.), Cold Spring Harbor perspectives in biology (pp. 1-16). New York, USA: Cold Spring Harbor Laboratory Press. doi: 10.1101/cshperspect.a000414

Silve, A., Leray, I., Poignard, C., \& Mir, L. M. (2016). Impact of external medium conductivity on cell membrane electropermeabilization by microsecond and nanosecond electric pulses. Scientific Reports, 6, 1-15. doi: https://doi.org/10.1038/srep19957

Singh, J., Singh, M., Singh, B., Nayak, M., \& Ghanshyam, C. (2017). Comparative analyses of prediction models for inactivation of Escherichia coli in carrot juice by means of pulsed electric fields. Journal of Food Science and Technology, 54(6), 1538-1544. doi: 10.1007/s13197-017-2585-9.

Skulberg, K. R., Skyberg, K., Eduard, W., Goffeng, L. O., Vistnes, A. I., Levy, F., \& Kjuus, H. (2001). Effects of electric field reduction in visual display units on skin symptoms. Scandinavian Journal of Work, Environment and Health, 27(2), 140-145. doi: 10.5271/sjweh.601. doi: 10.5271/sjweh.601.

Sweeney, D. C., Weaver, J. C., \& Davalos, R. V. (2018). Characterization of cell membrane permeability in vitro part I : Transport behavior induced by single-pulse electric fields. Technology in Cancer Research \& Treatment, 17, 1-15. doi: 10.1177/1533033818792491. 
